\title{
Migrating designs: matching product evolution to social migration
}

\begin{abstract}
Geographical migration appears to be an important factor in contemporary human life, bringing with it social changes for the people involved. We use the term "Social Migration" to point to the even larger numbers of people who are experiencing similar social changes regardless of physical location, as the populations of many countries experience rapid urbanisation and industralisation. This shift is challenge to designers. This paper describes initial work that examines both background literature and data, and investigates some practical cases where individuals, who find themselves in new environments, use and adapt household products to support both traditional and developing expectations. That work has allows us to propose some principles of product migration in practice, and techniques for designers to respond to social migration. These will be tested in a larger scale work.
\end{abstract}

Keyword: Cultural factors; Household product; Design 